\title{
Kablosuz EKG Cihazı Tasarımı ve Sinyal İşleme Teknikleri Kullanılarak Özniteliklerin Değerlendirilmesine Yönelik Web Sitesi Tasarımı
}

\author{
Sinem Abdioğlu ${ }^{*}$, Büşra Acar ${ }^{2}$, Ahmet Reşit Kavsaoğlu ${ }^{3}$ \\ 1Karabük Üniversitesi, Mühendislik Fakültesi, Biyomedikal Mühendisliği Bölümü, Karabük, Türkiye, (ORCID: 0000-0003-2973-1299), abdioglusinem61@gmail.com \\ ${ }^{2}$ KarabükÜniversitesi, Mühendislik Fakültesi, Biyomedikal Mühendisliği Bölümü, Karabük, Türkiye (ORCID: 0000-0003-1709-9070), busraacar78@,gmail.com \\ ${ }^{3}$ KarabükÜniversitesi, Mühendislik Fakültesi, Biiyomedikal Mühendisliği Bölümü, Karabük, Türkiye (ORCID: 0000-0002-4380-9075), kavsaoglu@hotmail.com
}

(3rd International Congress on Human-Computer Interaction, Optimization and Robotic Applications June 11-13, 2021)

(DOI: $10.31590 /$ ejosat.951988)

ATIF/REFERENCE: Abdioğlu, S., Acar, B. \& Kavsaoğlu, A.R. (2021). Kablosuz EKG Cihazı Tasarımı ve Sinyal İşleme Teknikleri Kullanılarak Özniteliklerin Değerlendirilmesine Yönelik Web Sitesi Tasarımı. Avrupa Bilim ve Teknoloji Dergisi, (26), 144-150.

$\ddot{O} \mathbf{z}$

Bu çalışmada, Wi-Fi haberleşme teknolojisi kullanılarak Elektrokardiyografi (EKG) sinyallerinin kablosuz olarak web ortamında görüntülenmesi ve gerekli sinyal işleme teknikleri kullanılarak bu sinyal hakkında yorum yapabilir dinamik bir sistem geliştirmek temel amaçtır. Bu doğrultuda ilk olarak Physionet.org web sayfasının sunduğu hazır EKG sinyalleri üzerinde çalışılmış ve bu sinyallerin öznitelik çıkarımları yapılmıştır. Aynı işlem AD8232 Kalp Atış Hızı Sensörü ile kaydedilen sinyaller üzerinde gerçekleştirilmiştir. Sinyaller işlenmeden önce sahip oldukları gürültülerden arındırılabilmesi için Kayan Ortalama Alma filtresinden geçirilmiştir. Elde edilen EKG sinyaline Pan-Tompkins algoritması uygulanmıştır. EKG sinyallerinin işlenmesi sonucu teşhis için kalp atım hızı ve kalp hız değişimi gibi öznitelikler elde edilmektedir. Çıkartılan bu öznitelikler erken teşhis ve tedavi imkânı sağlayabilmektedir. Bu çalışmada ortalama kalp atış hızına bağlı olarak ortaya çıkabilen Taşikardi ve Bradikardi durumlarının teşhisi gerçekleştirilmiş olup elde edilen sonuçlar web arayüzünde görüntülenmiştir. Bu sistemde web arayüzü, hasta ve doktor tipinde iki adet kullanıcı seçeneğine hizmet sunmaktadır. Hasta, kendine ait bütün ölçümleri; ölçümün gerçekleştirildiği tarih ve saat, ölçüm sonucu ortaya çıkan ortalama kalp atış hızı ve bu sayının standartlara göre yorumlanmış hali (Taşikardi, Brakidardi veya Normal) ve hastanın kendisine ait detayları (T.C. Kimlik Numarası, Telefon Numarası, Mail Adresi vb.) bu sistemde görüntüleyebilmektedir. Hastalar kalp atış hızı hakkında düzenli ve doğru bilgiye ulaşabilmekte ve gereksiz doktor randevuları bu sistem sayesinde ortadan kaldırabilmektedir. Doktor, randevuya gelen hastanın kalp sağlığı hakkında bazı tetkiklere gerek duymadan güvenilir ön bilgiye sahip olabilmektedir. Bu durum doktora zaman kazandırabilmekte ve daha fazla hastaya hizmet vermesine olanak sağlayabilmektedir.

\section{Wireless ECG Device Design and Website Design for the Evaluation of Features Using Signal Processing Techniques}

\begin{abstract}
In this study, the main objective is to display Electrocardiography (ECG) signals wirelessly on the web using Wi-Fi communication technology and to develop a dynamic system that can interpret this signal by using the necessary signal processing techniques. In this direction, firstly, the ECG signals provided by the Physionet.org web page were studied and the feature extractions of these signals were made. The same process was performed on the signals recorded with the AD8232 Heart Rate Sensor. Before the signals are processed,
\end{abstract}

\footnotetext{
* Sorumlu Yazar: Karabük Üniversitesi, Mühendislik Fakültesi, Biyomedikal Mühendisliği Bölümü, Karabük, Türkiye, ORCID: 0000-0003-29731299, abdioglusinem61@gmail.com
} 
they are passed through the Moving Averaging filter to remove any noise they may have. Pan-Tompkins algorithm is applied to the obtained ECG signal. As a result of processing ECG signals, features such as heart rate and heart rate change are obtained for diagnosis. These extracted features can provide early diagnosis and treatment opportunities. In this study, the diagnosis of Tachycardia and Bradycardia, which may occur depending on the average heart rate, was performed and the results were displayed on the web interface. In this system, the web interface serves for two user types as patient and doctor. All owned measurements; the date and time of the measurement, the average heart rate resulting from the measurement and the interpretation (Tachycardia, Brachydardy or Normal) of this number according to the standards and the patient's own details (T.R. Identity Number, Telephone Number, Mail Address, etc.) can be seen by the patient within this system. Patients can access regular and accurate information about heart rate. Unnecessary doctor appointments can be eliminated with the aid of this system. The doctor can have reliable preliminary information about the heart situation of the patient who comes to the appointment without the need for some examinations. This can save the doctor time to serve more patients.

Keywords: Wireless communication, ECG, Signal processing, Feature extraction, Pan-Tompkins algorithm.

\section{Giriş}

Kalp kası, kanı vücudun farklı bölgelerine pompalamak, gerekli kasılmayı ve genişlemeyi oluşturmak için bağımsız bir elektriksel uyarı sistemine ihtiyaç duymaktadır. Başka bir ifade ile kan basıncını oluşturmak ve kanı vücudun dolaşım sisteminde hareket ettirmek için elektrik sinyali verilir (Mazaheri V. \& Khodadadi, H., 2020). Kalpte bulunan kasların eş zamanlı olarak kasılması neticesinde yüksek genliğe sahip elektriksel bir işaret oluşur. Vücut üzerinden algılanan bu işaret $E K G$ olarak adlandırılamaktadır (Yazgan ,E. \& Korürek, M., 1996). EKG, elektrik sinyallerinin kalp tarafindan oluşturulan grafiksel bir kaydidir (Chee, J. \& Seow, S.C. 2020).

EKG non-invaziv olarak kardiyovasküler hastalıklar için modern tıpta en yaygın bulunan ve rutin olarak gerçekleştirilen tanı araçlarından biridir (Li, Y. et al., 2020). EKG sinyalleri kalp problemlerini ve anormalliklerini belirlemek için doktorlar tarafından büyük ölçüde kullanılmaktadır (Mazaheri, V. \& Khodadadi, H., 2020). EKG sinyallerinin işlenmesi ve değerlendirilmesi damardaki anormalliklerin tespit edilmesi, kalp kusurunun teşhisi ve hastalıkların tedavisinde faydalı bilgiler sağlar (Miao, F. et al., 2020). Örneğin; Heart Rate Variability (HRV) bir R noktasından, onu takip eden diğer R noktasına kadar geçen zaman aralığının grafiklenmesidir. Aynı zaman aralığında oluşan R tepeleri düşük HRV' ye yol açmaktadır. Düşük HRV' nin insan vücudundaki belirtileri; sürekli stres altında hissetme, çabuk yorulma ve adaptasyonda güçlük çekme olarak görülmektedir. HRV, otonom sinir sistemi (ANS) ve onun sempatik ve parasempatik dalları tarafindan düzenlenmektedir. ANS' nin sempatik kolu, insanı harekete geçirmeye, tepki vermeye ve performans göstermeye hazırlayan bir sistemdir. Parasempatik taraf ise, vücudun güçlenmesini ve iyileşmesini sağlayan dinlenme ve sindirim sistemi olarak karakterize edilmektedir. İki sistem arasındaki doğal etkileşim, kalbin farklı durumlara ve ihtiyaçlara hızlı bir şekilde yanıt vermesini sağlamaktadır. İnsanlar telefon konuşması yaparken, mesaj gönderirken veya internette gezinirken kablosuz haberleşmeden faydalanmaktadırlar (Cao, K. et al., 2021). Kablosuz haberleşme sistemleri, bir dizi hücresel baz istasyonu vasıtasıyla kullanıcılar arasında kablosuz iletişimi sağlamaktadır. Son yıllarda sağlık sektöründe kablo bağlantılarının karışıklığından doğan problemleri ortadan kaldırmak ve kablo maliyetini düşürmek için kablosuz iletişim araçlarının kullanımı yaygınlaştırılmaktadır.

Günümüzde yaşanan teknolojik gelişmelerden sağlık alanında da yararlanılmaktadır. Elektronik Sağlık Kaydı Sistemleri (ESK), Tele Sağlık, Tele Ameliyat ve Klinik Karar Destek Sistemleri gibi uygulamalar ile tıp alanında birçok kolaylık sağlanmaktadır. Özellikle kişiselleştirilmiş sağlık uygulamaları hem hasta hem de sağlı personeli arasında bir köprü kurmakla beraber sağlık personellerinin iş yükünü azaltmış ve hızlı teşhis-hızlı tedavi prensibinin benimsenmesine olanak sağlamıştır. Dünyamız her geçen gün hiç beklenmedik durumlarla karşı karşıya kalabilmektedir. Özellikle, Covid-19 salgınıyla birlikte bir kez daha anlaşılmıştır ki bir ülkenin sağlık sistemi o ülkenin temel yapı taşlarından bir tanesidir. Dolayısıyla sağlık sistemlerini hem donanımsal hem de yazılımsal olarak her daim canlı tutmak daha fazla önem kazanmaktadır. Bu süreçte özellikle 65 yaş üstü insanlar risk grubunda bulunan ve aynı zamanda kalp ve dolaşım hastalıklarının da en çok görüldüğü yaş grubudur. Ülkemizde ve dünyada gerçekleşen ölümlerin başlıca sebebi kalp ve damar hastalıklarına bağlı olarak gerçekleşmektedir. Bu sebeple kalp ve damar hastalıklarında erken tanı ve teşhisin önemi büyük ölçüde artmaktadır.

Literatürdeki benzer örnekler incelendiğinde; Vajihe Mazaheri ve Hamed Khodadadi göre bir EKG aritmi saptama sisteminde özellik çıkarma, özellik seçimi ve sınıflandırıcı yapımı olmak üzere üç ana prosedür vardır. Tek anahtar prosedür olarak, özellik çıkarma, giriş verilerini bir dizi özelliğe dönüştürür ve çoğu kalp hastalığının tespitinde önemli bir rol oynar (Jenkins, A.C. et al., 2008).

Çalışmaların çoğunda dalgacık analizinin yapıldığı görülmektedir. Israa Tawfic ve Sema Kayhan'ın yapmış oldukları Kablosuz EKG olarak ana başlık altında topladıkları çalışmaya göre Wireless body area network (WBAN) adı verilen insan vücudunun içinde ve dışında bulunan çeşitli tıbbi sensörleri ve cihazları bağlamak için Telemonitoring olarak çalışmak üzere tasarlanmış, amaca yönelik bir sensör ağıdır. Şu an mevcut elektronik olarak hasta izleme sistemi ile karşılaştırıldığında WBAN' ın iki adet avantajı bulunmaktadır. Bunlardan ilki taşınabilir izleme cihazlarını kullanarak hastaların hareketliliğidir; ikincisi, yerden bağımsız izleme olanağıdır. WBAN kullanıcın bilgilerini teknolojik aletlerde gösterebilme ve saklama özelliğine sahiptir (Tawfic, I. \& Kayhan, S., 2015). Salah S. Al-Zaiti ve arkadaşları tarafından yapılan çalışmalarındaki amaçları kablosuz EKG iletiminde mevcut ilerlemelerin güncel kanıtlarını, güncel sorunlarını ve potansiyel çözümlerini ve hasta sonuçları üzerindeki klinik etkisini sentezlemektir. Çalışmalarındaki ölçülen dijital EKG ideal olarak ham dijital formatında kablosuz olarak, yorumlama için uygun doktora gönderilmeden önce işleme yapmak için bir alıcı tarafına iletilir. 12 kurşun EKG elde edilen ve dijital olarak orijinal dalga formu ile bulaşan $(3 G)$ üçüncü nesil cep telefonu şebekesini kullanarak, uzaktan uyumlu bir alıcı tarafi için EKG cihazının modem biçimini temel alır. Alıcı tarafına EKG verilerini çözer, gözden geçirmek için EKG sinyalini yazdırır ve bir görüntü veya veri şeklinde doktorun cep telefonuna (veya e-postasına) gönderir (ikincisi telefonda yüklü bir veri görüntüleyici gerektirir). Daha 
çok bulut tabanlı sistemlere benzemektedir. Buradaki çalışma daha çok acil tıbbi hizmetler (EMS) için kullanılması uygun görünen çalışmadır (Al-Zaiti, S.S. et al., 2013).

\section{Materyal ve Metot}

$\mathrm{Bu}$ çalışmada; yazılım geliştirme mikrodenetleyici kartı olarak Arduino UNO, hastadan EKG verisi elde etmek için AD8232 EKG sensörü ve elde edilen öznitelikleri web ara yüzüne iletmesi için ESP8266(ESP-01) Wi-Fi seri haberleşme modülü kullanılmaktadır. EKG sinyalinin elde edilmesi için Arduino IDE, sinyallere Pan-Tompkins algoritması (Pan \& Tompkins, 1985) uygulanması için MATLAB, veri tabanı işlemleri için Microsoft SQL Server ve web arayüzünün oluşturulması için Visual Studio kullanılmıştır.

\subsection{Materyal}

Hastanın vücuduna yerleştirilen üç adet EKG elektrodu ve elektrotların bağlı olduğu AD8232 Kalp Atış Hızı Sensörü kullanılarak hasta üzerinden EKG sinyallerinin elde edilmesi Şekil 1'de blok diyagram olarak verilmiştir. Sinyaller çevresel ve fizyolojik koşullar sebebiyle birtakım gürültülere maruz kalmaktadır. Fizyolojik koşulların sebep olduğu gürültüler, hastanın ölçüm esnasında hareket etmesi, devam eden organ faaliyetleri ve insan vücudunun sahip olduğu deri direncinden kaynaklanmaktadır. Bu nedenlerden dolayı sinyal üzerinde kayan ortalama alma filtresi uygulanmıştır. $\mathrm{Bu}$ filtrenin kullanılmasındaki amaç; sürekli veri akışının olduğu durumlarda hata payını en aza indirmektir. Elde edilen sinyal MATLAB ortamına gönderilmiştir. Burada Pan-Tompkins algoritması kullanılarak öznitelik çıkarımları yapılmıştır. Öznitelikler ESP8266 Wi-Fi seri haberleşme modülü kullanılarak web arayüzüne gönderilmektedir. Web arayüzü, doktor ve hasta tipindeki kullanıcılara hizmet vermektedir. Bütün veriler ilgili veri tabanına kaydedilmektedir. Veri tabanı üzerinden önceki kayıtlar da doktor ve hasta tipindeki kullanıcılara gösterilebilmektedir.

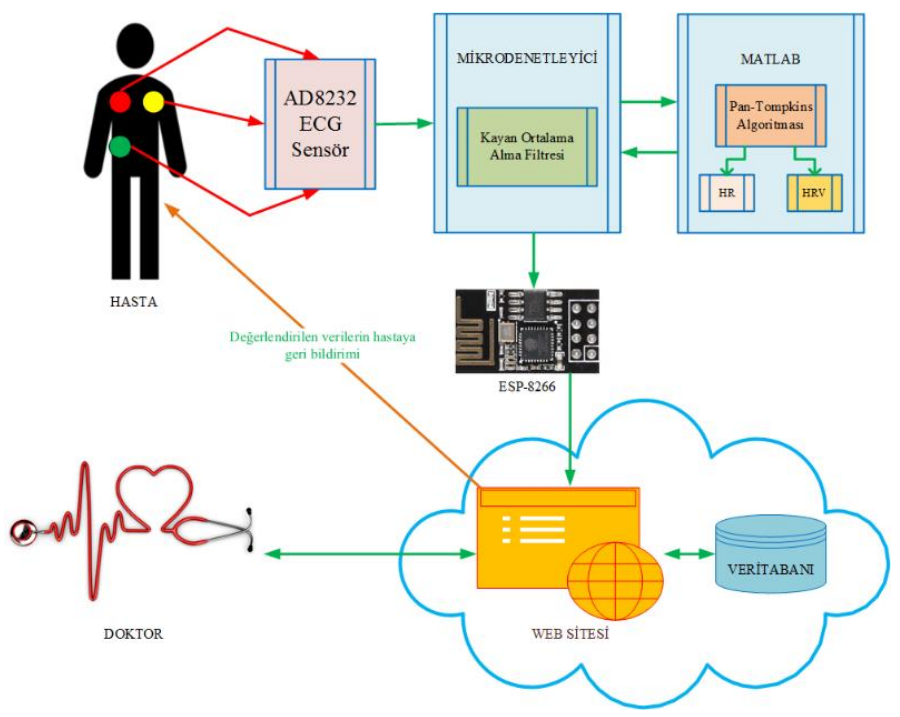

Şekil 1. Sisteme ait blok diyagram

\subsection{Metot}

Sisteme ait sinyal elde etme donanımı ve sinyal işleme arayüzü Şekil 2'de gösterilmektedir. EKG Modülü (AD8232), üç adet elektrot bağlantısıyla hastanın sağ göğsüne, sol göğsüne ve toprak görevi gören sağ boşluğa takılarak EKG sinyalleri elde edilmiştir. Sinyallere, yüksek miktarda gürültü içermesi ve düzenli olmaması sebebiyle kayan ortalama alma filtresi uygulanmıştır. Kayan ortalama alma filtresi, kısa vadeli dalgalanmaları düzeltmek ve uzun vadeli eğilimleri veya döngüleri vurgulamak için genellikle zaman serisi verileriyle birlikte hareketli bir ortalama alınması işlemidir.

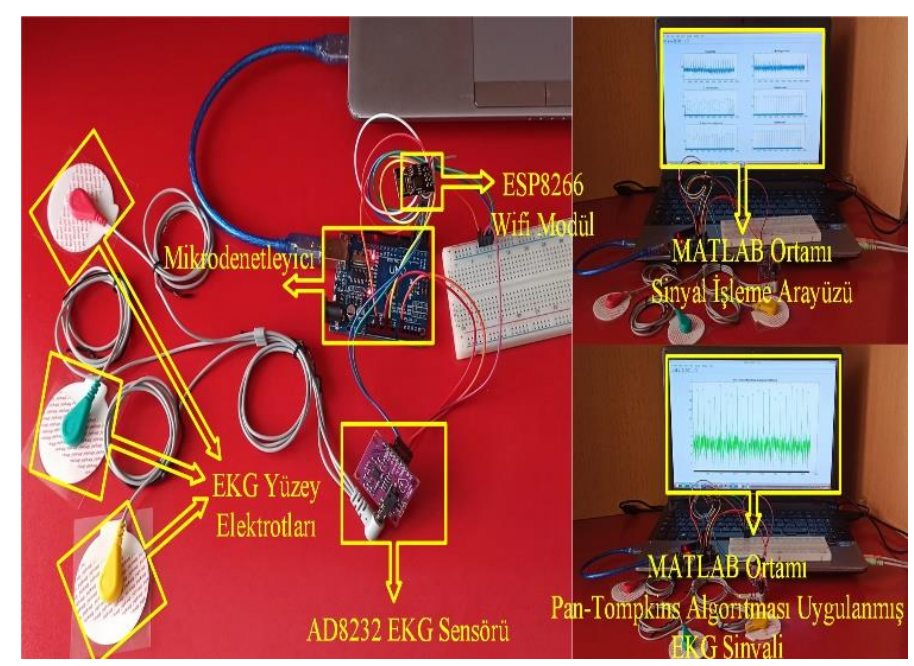

Şekil 2. Sisteme ait sinyal elde etme donanımı ve sinyal işleme arayüzü.

$\mathrm{Bu}$ çalışmada Pan-Tompkins algoritması kullanılmasının amacı; birbirini takip eden $\mathrm{R}$ tepeleri arasında geçen süreyi ölçmektir. Bir R tepesinden diğer R tepesine kadar geçen süre kalp ve damar hastalıklarının erken teşhisi için önemli bir veri sunmaktadır. $\mathrm{Bu}$ süre normal insanlarda çoğunlukla aynı olmamakla birlikte birbirine yakın değerlerde seyretmektedir. Taşikardi veya Bradikardi gibi kalp hastalığına sahip insanlarda ise düzensiz, çok kısa aralıklı veya çok uzun aralıklı seyredebilmektedir. $\mathrm{Bu}$ aralığın düzgün gözlemlenmesi erken teşhis sağlamaktadır. Algoritma, MATLAB ortamında gerçekleştirilmiş olup bu algoritma sonucunda ortalama kalp atış hızına ulaşılabilmektedir. Ortalama kalp atış hızının tespiti, kalbin çalışması hakkında bilgi sağlamaktadır. Dinlenme halindeki normal bir kalp dakikada 60-100 kez atmakta iken bu rakam egzersiz yaparken dakikada 130-150 atıma kadar çıkabilmektedir. Normal şartlarda kalp 60 atımdan daha az atıyorsa Bradikardi, 100 atımdan daha fazla atıyorsa Taşikardi riski oluşmaktadır. Devam eden Taşikardi atakları kalp krizine sebep olabilmektedir ve acil müdahale gerektiren bir durumdur. Bradikardi ataklarının devam etmesi ise düşük tansiyon sebebiyle bayılma, organların yetersiz çalışması ve hatta ölüme kadar gidebilmektedir. Şekil 3 'te Pan-Tompkins algoritması uygulanmış EKG sinyali gösterilmektedir.

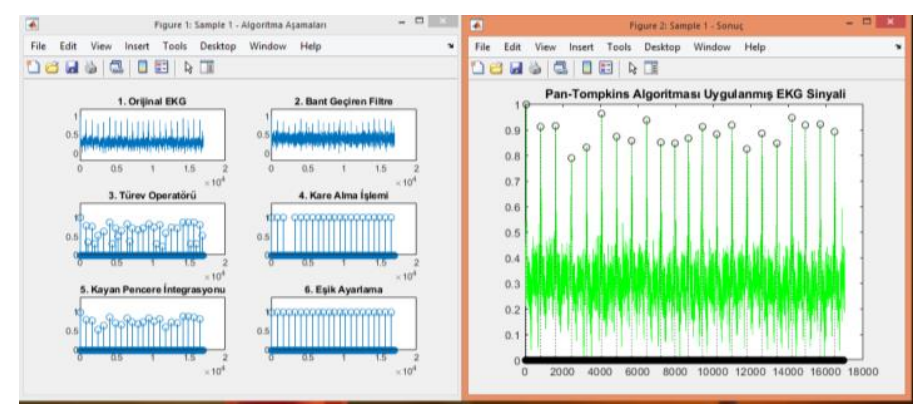

Şekil 3. Pan-Tompkins algoritması uygulanmış EKG sinyali.

Arduino ve MATLAB arasında seri haberleşme ile öznitelikler web arayüzüne iletilmektedir. Veri tabanı Microsoft 
SQL Server' da oluşturulmadan önce Şekil 4'te verilen EntityRelationship (ER) diyagramı çizilmiştir. ER diyagramı veri tabanında tutulan varlıkların ilişkilerini gösteren görsel bir ifade biçimidir.

"KULLANICILAR",

"OLCUMLER",

"TESHIS", "KULLANICI_TIPI", "TANSIYONOLCUM", "YORUM" ve "DEGER" isimli yedi adet tablo SQL Server'da oluşturulmuştur. KULLANICILAR tablosunda, oluşturulan dokuz adet sütun kullanıcıya ait bilgileri tutmaktadır. "Id" özelliği kullanıcıları birbirinden ayırt etmek için "Ad" ve "Soyad" sütunları, kullanıcının isim ve soyisim bilgilerini almak için "T.C.", "Sifre", "eMail", "Telefon" ve "DogumTarihi" kullanıcı hakkında depolanan diğer verilerdir. "AktifMi" özelliği ise kullanıcının sistemde aktif ya da pasif olma durumunu kontrol etmek amaciyla depolanmaktadır. "KULLANICI_TIPI" isimli tabloda "Id" sütunu aynı görevi karşılarken "Tip" sütunu kullanıcının "Hasta" veya "Doktor" tipinde olduğunu kaydetmektedir. TESHIS tablosunda da diğer tablolarda olduğu gibi "Id" aynı amaçla kullanılmakla beraber "Ad" sütunu Bradikardi, Taşikardi veya Normal tipinde özniteliklerin yorumlanmıș hallerini depolamaktadırlar. Son olarak "OLCUMLER" isimli tabloda "Id" ve "AktifMi" sütunları aynı görevi üstlenirken "OlcumTarihi" ölçümün yapıldığı tarihi ve saati, "MMdosyaYolu" isimli sütun ise hastaya ait kişisel bilgileri ve ölçüm bilgilerini içeren bir pdf dosyasının yolunu tutmak amacıyla olușturulmuştur. Dosyanın direkt olarak "pdf" formatında yüklenmeyip dosya yolunun tutulmasının nedeni sistemin daha hizlı ve daha performanslı çalışabilmesi içindir. Diyagramda bulunan "SilindiMi" isimli sütun ise ilgili kaydın silinme durumunu kontrol etmektedir. Hastanın girdiği tansiyon değerlerini kayıt altında tutmak için "TANSIYONOLCUM" isimli tablo, Hesaplanan ortalama kalp atış değerlerinin tutulması için "DEGER" isimli tablo ve ortalama kalp atış hızına ait yorumlanmış veriyi tutmak için "YORUM" isimli tablo oluşturulmuştur.

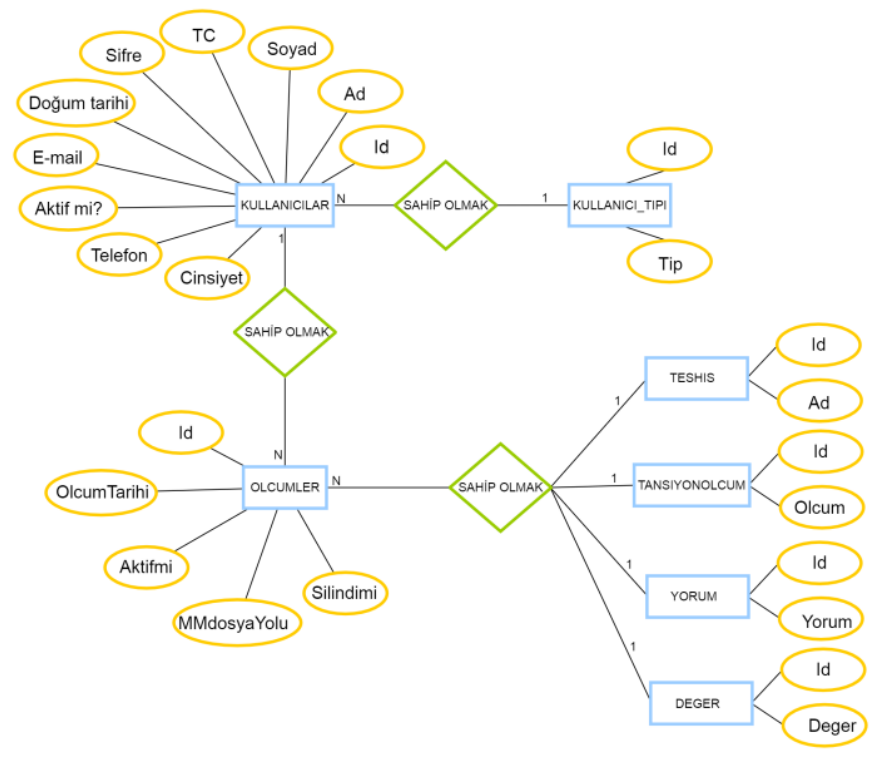

\section{Şekil 4. ER Diyagramı}

Web arayüzü C\# diliyle ve NET Core Framework ile yazılmıştır. Web arayüzü ile veri tabanı bağlantısı sağlanmıştır. Böylece önceden yapılan bütün ölçümler veri tabanına kaydedilmiş ve gerekli görülmesi durumunda bu kayıtlar kullanıcıya gösterilmektedir. $\mathrm{Bu}$ sistem veri tabanı alt yapısı sayesinde büyük bir veri kaydı depolamaktadır. Bu veri seti kalp ve damar hastalıklarına bağlı ölüm oranlarını azaltmak ve sağlık sistemlerini iyileştirmek gibi çeşitli amaçlara hizmet edebilmektedir. Ayrıca sistemde yaş, cinsiyet, toplam kolestrol, sistolik kan basınc1 ve sigara kullanma parametrelerine bakılarak kalp krizi riski hesaplaması yapılmaktadır.

Hasta tipindeki kullanıcıya ait arayüz Şekil 5'te verilmektedir. Sayfanın sol üst köşesinde hastanın isim-soyisim, yaş ve cinsiyet bilgileri bulunmaktadır. $\mathrm{Bu}$ alanın altında ise hastaya ait son ölçümün bilgileri yer almaktadır. Hasta bu ekrana bakarak son ölçümü hakkında koyulan teşhise ulaşabilmekte ve daha detaylı bilgi edinmek istemesi halinde "pdf indir" butonuna basarak yazılı bir belge elde edebilmekte, dilerse bu pdf dosyasını doktor muayenesi sırasında gösterebilmektedir. Hasta daha önceden kaydetmiş olduğu ölçümlerine ulaşmak istemesi durumunda "Basınız" isimli butona basarak açılır tablodan bu kayıtlara ulaşabilmektedir. Aynı zamanda bu tabloda, ölçümün gerçekleştirildiği tarihi, elde edilmiş ölçüm değeri, bu değere bağlı teşhisi, ölçüm sırasında kendi isteğiyle girdiği tansiyon değerini ve tansiyon değerinin yorumlanmış halini görebilmektedir. Bu bilgilerin veri tabanında tutulmasının sebebi hastanın elektronik sağlık geçmişini oluşturmak amacın taşımaktadır.
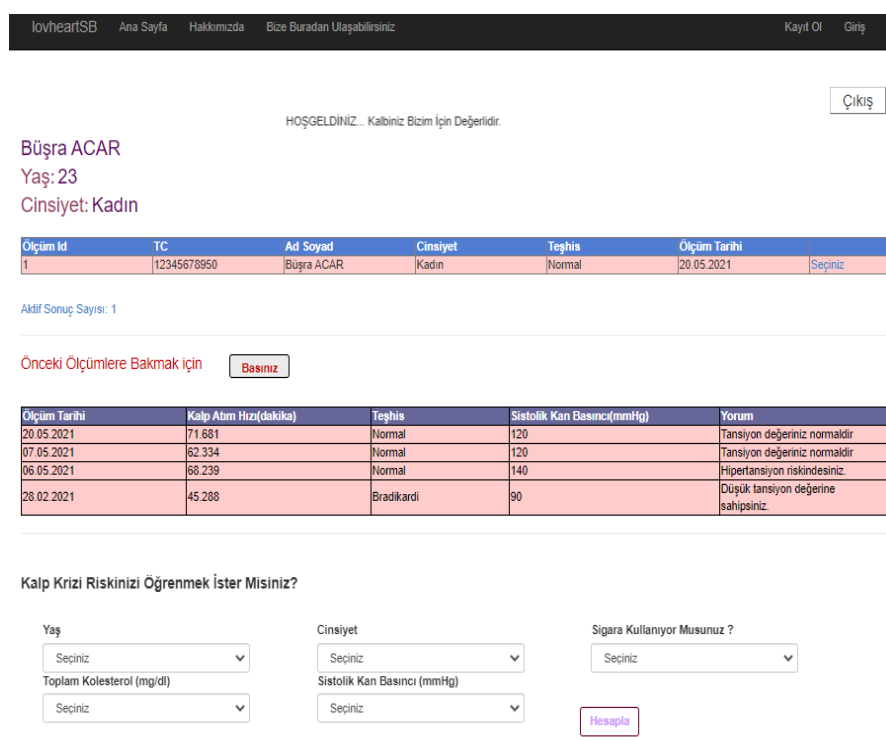

Şekil 5. Hasta tipinde bir kullanıclya ait arayüz.

Bir doktorun muayene esnasında hastaya ait geçmiş verilere ulaşabilmesi teşhis sürelerini kısaltırken doktorun iş yükünü de azaltmaktadır. Hasta ev ortamında konforlu, güvenilir ve ekonomik bir şekilde hem ölçümlerini yapabilmekte hem de teşhisini gerçekleştirebilmektedir. Hasta arayüzünde ek olarak "Kalp Krizi Riskinizi Öğrenmek İster Misiniz?" isimli bir alan bulunmaktadır. Hasta kendine ait istenilen verileri bu alana girdiğ takdirde kalp krizi geçirme riskini öğrenebilmektedir. Bu alanda hastadan girmesi beklenen veriler, e-Nabız sisteminin de kullandığı verilerdir.

Doktor tipindeki kullanıcıya ait arayüz Şekil 6'da yer almaktadır. Hasta sayfasında da olduğu gibi sol üst köşede doktora ait isim-soyisim bilgisi bulunmaktadır. Bu alanın altında, doktor takibini yaptı̆ğ hastaları ve hastalara ait ölçümleri görebilmektedir. Detaylı inceleme yapmak istemesi durumunda "EKG Sinyalini Görüntüle" isimli butona basarak, EKG sinyalinin görüntüleyebilmektedir. Böyle bir sistemin doktora sağlayacağı faydalar; iş yükünün azalması, zaman kazanımı ve daha fazla hastaya hizmet verebilme şeklinde sıralanabilmektedir. 


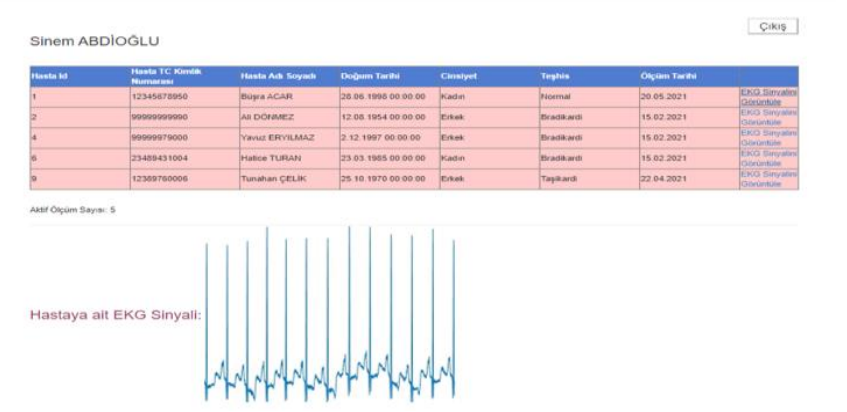

Tablo 1'de karşılaştırılmaktadır. Karşılaştırma kriteri olarak 6 farklı özellik belirlenmiştir. Bu özellikler yapılan çalışmaların güncel teknolojisi ve doktordan bağımsız olarak hastaya kalpdamar verilerinin değerlendirme bilgisini verebilmesi ile gömülü sistemler ile bütünleştirilmiş HR sensörleri vb sağlık bilgisi sensörleri ile bulunduğu ortamdan web arayüzüne sadece verilerini göndererek değerlendirme sonucu alabilmesi üzerine oluşturulmuştur. Pan-Tompkins algoritmasının kullanılması da sensör ölçümlerinin hassasiyetini arttırmaya yöneliktir.

Şekil 6. Doktor tipinde bir kullanıcıya ait arayüz.

Benzer çalışmalardan bazıları, mevcut çalışmanın literatüre katlkılarını belirtmek ve güncel farklılıklarını sunabilmek için

Tablo 1. Hasta kullanıcı sağlık verilerinin işlenerek değgerlendirme sonucunun Web arayüzü ile sunulmasını să̆layan çalışmaların karşılaştırılması.

\begin{tabular}{|c|c|c|c|c|c|c|}
\hline$\underbrace{\text { Özellikler }}_{\text {Çalışma }}$ & HR Algoritma & Haberleşme Türü & $\begin{array}{l}\text { Kullanıcı/ Doktor } \\
\text { Web Arayüzü }\end{array}$ & $\begin{array}{c}\text { Veri } \\
\text { depolama }\end{array}$ & $\begin{array}{c}\text { Veri Alma } \\
\text { Taşınabilir(T)/ } \\
\text { Sabit(S) } \\
\end{array}$ & $\begin{array}{c}\text { Hastaya } \\
\text { Online } \\
\text { Geribildirim } \\
\end{array}$ \\
\hline Makale Çalışması & $\begin{array}{c}\text { Pan-Tompkins ile } \\
\text { HR ve HRV } \\
\text { belirleme }\end{array}$ & Wifi + Mobil & Hasta + Doktor & $S Q L$ & $T$ & $\sqrt{ }$ \\
\hline $\begin{array}{c}\text { Kahani, N., Elgazzar, } \\
\text { K., \& Cordy, J. R. } \\
\text { (2016) }\end{array}$ & 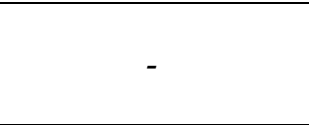 & Kablolu & Hasta + Doktor & Bulut & $S$ & $\sqrt{ }$ \\
\hline $\begin{array}{c}\text { Raj, C., Jain, C., \& } \\
\text { Arif, W. (2017) }\end{array}$ & - & Kablolu & Doktor & Bulut & $T$ & $\sqrt{ }$ \\
\hline $\begin{array}{l}\text { Khan, M. M., \& } \\
\text { Karim, R. (2020) }\end{array}$ & - & Kablolu-Mobil & Hasta + Doktor & - & - & $\sqrt{ }$ \\
\hline $\begin{array}{c}\text { Sengan, S., } \\
\text { Kamalam, G. K., } \\
\text { Vellingiri vd (2020) }\end{array}$ & - & Kablolu & Hasta + Doktor & $S Q L$ & $S$ & $\sqrt{ }$ \\
\hline Taştan, M. (2018) & $\begin{array}{c}\text { Inter Beat Interval } \\
\text { (IBI) }\end{array}$ & Bluetooth + Wifi & Hasta + Doktor & Bulut & $T$ & $\sqrt{ }$ \\
\hline $\begin{array}{c}\text { Jong, G. J., \& } \\
\text { Horng, G. J. (2017) }\end{array}$ & Fuzzy & Bluetooth + Wifi & Hasta + Doktor & Bulut & $S$ & $\sqrt{ }$ \\
\hline $\begin{array}{l}\text { Molina, E., Torres, } \\
\text { C. E. S. vd. (2020) }\end{array}$ & EEG Cihazı & - & Doktor & $S Q L$ & $S$ & - \\
\hline $\begin{array}{c}\text { Kirbaş, İ., \& } \\
\text { Bayilmiş, C. (2012) }\end{array}$ & $M A T L A B$ & Wifi & Hasta+Doktor & $S Q L$ & $T$ & $\sqrt{ }$ \\
\hline $\begin{array}{c}\text { Hussein, A. F., vd. } \\
\text { (2018) }\end{array}$ & $\begin{array}{c}\text { Pan-Tompkins QRS } \\
\text { belirleme }\end{array}$ & Bluetooth & Hasta + Doktor & Bulut $+S Q L$ & $T$ & $\sqrt{ }$ \\
\hline $\begin{array}{l}\text { Quintero, L., vd. } \\
\text { (2019) }\end{array}$ & $\begin{array}{l}\text { R tepesi için Argmax } \\
\text { fonksiyonu }\end{array}$ & Bluetooth + Mobil & Hasta & $\begin{array}{c}\text { Log } \\
\text { dosyasl }\end{array}$ & $T$ & $\sqrt{ }$ \\
\hline $\begin{array}{l}\text { Kirtana, R. N., \& } \\
\text { Lokeswari, Y. V. } \\
(2017) \\
\end{array}$ & $\begin{array}{l}\text { Inter Beat Interval } \\
\text { (IBI) }\end{array}$ & Bluetooth + Wifi & Hasta & $S Q L$ & $T$ & - \\
\hline $\begin{array}{c}\text { Zhang, Q., Zhou, D., } \\
\text { \& Zeng, X. (2017) }\end{array}$ & $\begin{array}{c}\text { Butterworth }+M L \\
\text { enabled framework } \\
\text { (MLEF) }\end{array}$ & $U S B$ & - & - & $T$ & - \\
\hline Alafeef, M. (2017) & $M A T L A B$ & - & - & - & $T$ & - \\
\hline $\begin{array}{c}\text { Andreadis, I. I., \& } \\
\text { Nikita, K. S. (2019) } \\
\end{array}$ & - & Wifi & Hasta + Doktor & Veri tabanı & $T$ & $\sqrt{ }$ \\
\hline Chen, C. M. (2011) & $\begin{array}{c}\text { Pan-Tompkins } Q R S \\
\text { belirleme }\end{array}$ & Wifi & Doktor & Web Server & $T$ & - \\
\hline
\end{tabular}




\section{Tartışma}

T. K. Kho ve arkadaşları öneri olarak sundukları hasta üzerinden alınan EKG sinyalini aldiktan sonra Bluetooth yöntemiyle veriyi transfer etmişlerdir. Geliştirdikleri uygulama programı, bu sinyali grafik şeklinde karşı taraftaki bilgisayarda görüntülemektedir. (Kho, T. K. et al.,2005).

Angela C. Jenkins ve arkadaşları ise bir Toksikoloji çalışma ortaminda harici, Bluetooth tabanl, EKG telemetri sistemini değerlendirmektir. $\mathrm{Bu}$ sistem, aynı odada 36 hayvana kadar EKG'lerin eşzamanlı olarak toplanmasını sağlar. Ayrıca, sistemin sinırsiz insan olmayan primatlarda (Nhps) en az 24 saat boyunca EKG verilerini sürekli olarak elde etme yeteneği ve diğer kablosuz iletişim cihazlarıyla Wi-Fi gibi etkileşim potansiyeli hakkında değerlendirmeler yapılmıştır. Hayvanlar arasında sinyal paraziti gözlenmemiştir. Ayrı bir deneyde, kablosuz sinyal Bluetooth ve Wi-Fi sistemleri arasındaki dikkat test edilmiştir ve sonuç olarak Bluetooth cihazlarının bir Wi-Fi kablosuz ağ sistemi ile parazitsiz bir arada var olduğu bulunmuştur. Görülmüştür ki telemetri, fizyolojik parametrelerin (EKG, kan basınc1, vücut 1S1s1) kaydedilmesine izin veren terminal olmayan bir tekniktir (Jenkins, A.C. et al., 2019).

Literatürden alınan Tablo 1'deki çalışmalar incelendiğinde oluşturulan çalışmanın; Pan-Tompkins algoritması kullanılması, kablosuz haberleşme türü olarak Wi-Fi tercih edilmesi, taşınabilir veri toplama sistemi olması, hasta ve doktor kullanıcı arayüzü ile hastaya değerlendirilen verilerin çevrimiçi olarak sunulabilmesi özellikleri farklılık oluşturmaktadır. Çalışmanın literatürdeki çalışmalardan bariz şekilde ayrılmasını sağlayan nokta, EKG sinyallerinin mikrodenetleyicide filtrelenerek MATLAB ortamında Pan-Tompkins algoritması uygulandıktan sonra Web sitesinde hasta kullanic1 verisi olarak kaydedilip değerlendirildikten sonra hastaya değerlendirme bilgisi olarak aktarılmasıdır. $\mathrm{Bu}$ yöntem ile doktor ve hasta doğrudan birbirleri ile iletişime geçmeleri yerine sonuç odaklı pratik bir tedavi sunulabilmektedir. Ayrıca çalışmada herhangi bir tıbbi cihaz ve doktor muayenesine ihtiyaç duyulmaksızın EKG sinyallerinden çıkarım yapılmakta ve bu çıkarımların sonucu ölçümü yapan kişi tarafından görüntülenebilmektedir. Veri tabanı sayesinde bütün değerler kayıt altına alınmakta ve bu kayıtlar kişinin kalp sağlığı hakkında önemli bilgileri içeren bir veri seti haline getirilmektedir. $\mathrm{Bu}$ konuda var olan eksiklik bu çalışma ile giderilmeye çalışılmıştır.

\section{Sonuç}

$\mathrm{Bu}$ çalışma, kullanılmakta olan elektronik sağlık sistemlerinin eksik taraflarını tamamlamak amacıyla geliştirilmiştir. Günümüzde kullanılan elektronik sağlık uygulamalarında, kullanıcıya ait raporlar görüntülenebilmekte fakat bu raporlara ait uzman görüşü için hastanın mutlaka doktor randevusu alması gerekmektedir. Bu durum bazen gereksiz doktor randevularına ve buna bağlı olarak hastahane yoğunluklarına yol açabilmektedir. Hastanın, çok ciddi olmayan durumlarda uzman doktor görüşüne herhangi bir sağlik kuruluşuna başvurmadan ulaşabilmesi bu çalışmanın önemini arttırmakla birlikte doktorların iş yükünü ve tanı koyma süresini de azaltmaktadır. Diğer yandan hastalara kişiselleştirilmiş sağlık hizmetlerini ekonomik ve ulaşılabilir olarak sunabilecek bir çalışmadır. Acil tıbbi müdahele gerektiren durumlarda kişiselleştirilmiş sağlık hizmetlerinin önemli bir rolü bulunmaktadır. Anlık geri bildirim özelliği sayesinde birçok hastaya hızlıca ulaşılabilmekte ve tedavi edilebilmektedir. $\mathrm{Bu}$ çalışma kişiselleştirilmiş sağlık uygulamalarının yüksek ulaşılabilirlik seviyesine getirilmesini hedeflemekle birlikte hasta ve doktor arasında dijital bir köprü görevi görmektedir.

Ayrica bu sistem sayesinde uzman yazılım personeline de yer verilip EKG'den elde edilebilecek ilave öznitelikler ile doktor yorumlarının birlikte analizinin gerçekleştirilebilmesi mümkün k1lınabilecektir. Böylelikle bu web site tasarımında hasta kullanıcıları arttıkça sürekli genişleyen veri tabanından oluşturulacak dinamik veri seti, yapay sinir ağları (YSA) yöntemleri ile eğitilerek doktor yorumlarını tahmin edebilen bir web site tasarımına dönüştürülebilecektir.

\section{Teșekkür}

$\mathrm{Bu}$ çalışma TÜBİTAK Bilim İnsanı Destek Programları Başkanlığı tarafından yürütülen "2209-A Üniversite Öğrencileri Araştırma Projeleri Destekleme Programı" 2020/2 dönemi kapsamında hibe desteği almaya hak kazanmıştır. Değerli destekleri için TÜBİTAK kurumuna teşekkürlerimizi sunarız.

\section{Kaynakça}

Alafeef, M. (2017). Smartphone-based photoplethysmographic imaging for heart rate monitoring. Journal of medical engineering \& technology, 41(5), 387-395.

Al-Zaiti, S.S., Shusterman, V., Carey, M.G. (2013). Novel technical solutions for wireless ECG transmission \& analysis in the age of the internet cloud, Journal of Electrocardiology, $46(6), 540-54$.

Andreadis, I. I., \& Nikita, K. S. (2019). Tele-, Mobile-and WebBased Technologies in Cardiovascular Medicine. In Cardiovascular Computing-Methodologies and Clinical Applications (pp. 261-277). Springer, Singapore.

Cao, K., Hu, T., Li, Z., Zhao, G., \& Qian, X. (2021). Deep multitask learning model for time series prediction in wireless communication. Physical Communication, 44(December). https://doi.org/10.1016/j.phycom.2020.101251

Chen, C. M. (2011). Web-based remote human pulse monitoring system with intelligent data analysis for home health care. Expert Systems with Applications, 38(3).

Goldberger, A.L., Amaral, L.A.N., Glass, L., Hausdorff, J.M., Ivanov, P.C.H., Mark RG, Mietus, J.E., Moody, G.B., Peng, C.K., Stanley, H.E. PhysioBank, PhysioToolkit, and PhysioNet: Components of a New Research Resource for Complex Physiologic Signals. Circulation 101(23): e215e220

Hussein, A. F., Burbano-Fernandez, M., Ramírez-González, G., Abdulhay, E., \& De Albuquerque, V. H. C. (2018). An automated remote cloud-based heart rate variability monitoring system. IEEE Access, 6, 77055-77064.

Jenkins, A.C., Mitchell, R. D. Sarazan. (2008). Noninvasive ECG telemetry using Bluetooth ${ }^{\circledR}$ technology in concious nonhuman primates in a toxicology study setting, Journal of Pharmacological and Toxicological Methods, 461, 152-153

Jong, G. J., \& Horng, G. J. (2017). Fuzzy Inference Engine Integrated with Blood Pressure and Heart Variability for Medical Web Platform. Wireless Personal Communications, 92(4), 1695-1712.

Kahani, N., Elgazzar, K., \& Cordy, J. R. (2016, April). Authentication and access control in e-health systems in the cloud. In 2016 IEEE 2nd International Conference on Big Data Security on Cloud (BigDataSecurity), IEEE 
International Conference on High Performance and Smart Computing (HPSC), and IEEE International Conference on Intelligent Data and Security (IDS) (pp. 13-23). IEEE.

Khan, M. M., Karim, R. (2020, December). Development of Smart e-Health System for COVID-19 Pandemic. In 2020 23rd International Conference on Computer and Information Technology (ICCIT) (pp. 1-6). IEEE.

Kirbaş, İ., \& Bayilmiş, C. (2012). HealthFace: A web-based remote monitoring interface for medical healthcare systems based on a wireless body area sensor network. Turkish Journal of Electrical Engineering \& Computer Sciences, 20(4), 629-638.

Kirtana, R. N., \& Lokeswari, Y. V. (2017, January). An IoT based remote HRV monitoring system for hypertensive patients. In 2017 International Conference on Computer, Communication and Signal Processing (ICCCSP) (pp. 1-6). IEEE.

Kong, D., Zhu, J., Wu, S., Duan, C., Lu, L., \& Chen, D. (2019). A novel IRBF-RVM model for diagnosis of atrial fibrillation. Computer Methods and Programs in Biomedicine, 177, 183192. https://doi.org/10.1016/j.cmpb.2019.05.028

Li, Y., Qu, Q., Wang, M., Yu, L., Wang, J., Shen, L., \& He, K. (2020). Deep learning for digitizing highly noisy paper-based ECG records. Computers in Biology and Medicine, 127(October),

104077. https://doi.org/10.1016/j.compbiomed.2020.104077

Mazaheri, V., \& Khodadadi, H. (2020). Heart arrhythmia diagnosis based on the combination of morphological, frequency and nonlinear features of ECG signals and metaheuristic feature selection algorithm. Expert Systems with Applications, 161(December), 1-39. https://doi.org/10.1016/j.eswa.2020.113697

Miao, F., Wen, B., Hu, Z., Fortino, G., Wang, X. P., Liu, Z. D., Tang, M., \& Li, Y. (2020). Continuous blood pressure measurement from one-channel electrocardiogram signal using deep-learning techniques. Artificial Intelligence in Medicine, 108(August), 1-29. https://doi.org/10.1016/j.artmed.2020.101919

Molina, E., Torres, C. E. S., Salazar-Cabrera, R., López, D. M., \& Vargas-Cañas, R. (2020). Intelligent telehealth system to support epilepsy diagnosis. Journal of Multidisciplinary Healthcare, 13, 433.

Pan, J., \& Tompkins, W. J. (1985). A real-time QRS detection algorithm. IEEE transactions on biomedical engineering, (3), 230-236.

Quintero, L., Papapetrou, P., Muñoz, J. E., \& Fors, U. (2019, November). Implementation of Mobile-Based Real-Time Heart Rate Variability Detection for Personalized Healthcare. In 2019 International Conference on Data Mining Workshops (ICDMW) (pp. 838-846). IEEE.

Raj, C., Jain, C., \& Arif, W. (2017, March). HEMAN: Health monitoring and nous: An IoT based e-health care system for remote telemedicine. In 2017 International Conference on Wireless Communications, Signal Processing and Networking (WiSPNET) (pp. 2115-2119). IEEE.

Sengan, S., Kamalam, G. K., Vellingiri, J., Gopal, J., Velayutham, P., \& Subramaniyaswamy, V. (2020). Medical information retrieval systems for e-Health care records using fuzzy based machine learning model. Microprocessors and Microsystems, 103344.

Kho, T. K., Besar, R., Tan, Y. S., Tee, K. H. \& Ong, K. C. "Bluetooth-enabled ECG Monitoring System", in TENCON, 2005, pp. 1-5, 21-24 Nov. 2005.

Taştan, M. (2018). Iot based wearable smart health monitoring system. Celal Bayar Üniversitesi Fen Bilimleri Dergisi, 14(3), 343-350.

Rajendra, U., AcharyaJasjit S., SuriJos A., SpaanShankar, E., Krishnan, M. (2007). Advances in Cardiac Signal Processing, SpringerLink.com, 441, 121-165. https://link.springer.com/book/10.1007/978-3-540-366751 \#toc

Yazgan, E., \& Korürek, M. (1996). Tıp Elektroniği. 373, 90-102.

Zhang, Q., Zhou, D., \& Zeng, X. (2017). Highly wearable cuffless blood pressure and heart rate monitoring with single-arm electrocardiogram and photoplethysmogram signals. Biomedical engineering online, 16(1), 1-20. 